\title{
Galectin 3 regulates HCC cell invasion by RhoA and MLCK activation
}

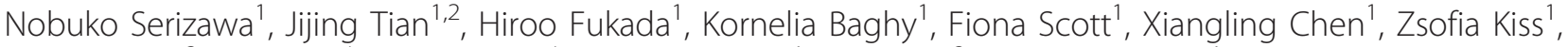 \\ Kristin Olson ${ }^{3}$, Dan Hsu', Fu-Tong Liư ${ }^{4}$, Natalie J Török', Bin Zhao ${ }^{2}$ and Joy X Jiang ${ }^{1}$
}

Hepatocellular carcinoma (HCC) carries a poor prognosis with no effective treatment available other than liver transplantation for selected patients. Vascular invasion of HCC is one of the most important negative predictor of survival. As the regulation of invasion of HCC cells is not well understood, our aim was to study the mechanisms by which galectin 3, a $\beta$-galactosidase-binding lectin mediates HCC cell migration. HCC was induced by N-diethylnitrosamine in wild-type and galectin $3^{-1-}$ mice, and tumor formation, histology, and tumor cell invasion were assessed. The galectin $3^{-1-}$ mice developed significantly smaller tumor burden with a less invasive phenotype than the wild-type animals. Galectin 3 was upregulated in the wild-type HCC tumor tissue, but not in the surrounding parenchyma. Galectin 3 expression in HCC was induced by NF-KB transactivation as determined by chromatin immunoprecipitation assays. In vitro studies assessed the pro-migratory effects of galectin 3. The migration of hepatoma cells was significantly decreased after transfection by the galectin 3 siRNA and also after using the Rho kinase inhibitor Y-27632. The reorganization of the actin cytoskeleton, RhoA GTPase activity and the phosphorylation of MLC2 (myosin light chain 2) were decreased in the galectin 3 siRNA-transfected cells. In addition, in vitro and in vivo evidence showed that galectin 3 deficiency reduced hepatoma cell proliferation and increased their apoptosis rate. In conclusion, galectin 3 is an important lectin that is induced in HCC cells, and promotes hepatoma cell motility and invasion by an autocrine pathway. Targeting galectin 3 therefore could be an important novel treatment strategy to halt disease progression.

Laboratory Investigation (2015) 95, 1145-1156; doi:10.1038/labinvest.2015.77; published online 6 July 2015

Hepatocellular carcinoma (HCC) is the third leading cause of cancer mortality worldwide, ${ }^{1}$ and its incidence and mortality rates continually rise. In the United States it has the fastest growing death rate amongst all cancers. ${ }^{2}$ The only curative treatment approach is liver transplantation that is only available to the selected patients with localized early stage disease. HCC has a high metastatic and invasive potential leading to early recurrence after local ablative therapies or resection. The pathomechanism governing the invasiveness of HCC is poorly understood, and thus far there are no treatment strategies that can prevent HCC invasion. Galectin 3 is a unique $30 \mathrm{kDa}$ molecule with a chimeric structure. ${ }^{3}$ As a member of the $\beta$-galactosidase binding lectin family, galectin 3 (also known as MAC-2) controls crucial cellular functions including cell adhesion, survival/apoptosis, regulation of adaptive immunity, and macrophage activation. ${ }^{4-6}$ Galectin
3 also has a role in the activation and transdifferentiation of hepatic stellate cells to myofibroblasts and in the progression of liver fibrosis. ${ }^{7,8}$ Although normal hepatocytes do not express galectin 3 , its expression was shown to be induced in patients with HCC, ${ }^{9,10}$ and in hepatocytes neighboring the fibrotic stroma in cirrhotic livers. ${ }^{9}$ In addition, tumorassociated macrophages in other tissues were also described as important sources of galectin $3 .{ }^{11}$ In patients with HCC higher galectin 3 expression portended a worse overall survival. ${ }^{10}$ As the role of the galectin 3 in HCC progression has not been addressed, our goal was to assess the molecular mechanism by which galectin 3 contributes to tumor cell invasion. We have recently shown that galectin 3 binds to integrin $\alpha v \beta 3$ suggesting it has a role in ligand clustering on the cell surface, referred to as 'galectin lattice.' ${ }^{2}$ As integrins can directly signal to Rho GTPases modulating the

${ }^{1}$ Division of Gastroenterology and Hepatology, Department of Internal Medicine, UC Davis Medical Center, Sacramento, CA, USA; ${ }^{2}$ State Key Laboratory of Environmental Chemistry and Ecotoxicology, Research Center for Eco-environmental Sciences, Chinese Academy of Sciences, Beijing, China; ${ }^{3}$ Department of Pathology, UC Davis Medical Center, Sacramento, CA, USA and ${ }^{4}$ Department of Dermatology, UC Davis Medical Center, Sacramento, CA, USA

Correspondence: Dr JX Jiang, MD, PhD, Division of Gastroenterology and Hepatology, Department of Internal Medicine, UC Davis Medical Center, PSSB, 4150 V Street, Suite 3500, Sacramento, CA 95817, USA.

E-mail: xiaosong.jiang@ucdmc.ucdavis.edu

Received 8 September 2014; revised 31 March 2015; accepted 13 May 2015 
phosphorylation of the myosin light chain (MLC) we postulated that galectin 3 regulates the invasiveness of HCC cells by a RhoA/Rho kinase (ROCK) pathway. ${ }^{13}$

Herein we show that galectin 3 is induced by an NF- $\kappa$ Bdependent mechanism in HCC, and that galectin $3^{-1-}$ mice exhibit significantly smaller tumor burden after HCC induction with a less invasive phenotype. Galectin 3-induced RhoA/ ROCK activation was required for the phosphorylation of the MLC2, leading to actin reorganization and migration of hepatoma cells. We conclude that galectin 3 is an important regulator of cell invasion during HCC progression.

\section{MATERIALS AND METHODS}

\section{Animals and Analysis of HCC Growth}

Galectin $3^{-1-}$ mice (kindly provided by Fu-Tong Liu, Department of Dermatology, UC Davis) in a C57/B6 background were generated by gene targeting technology, as described. ${ }^{14}$ As controls, age and sex-matched wild-type (wt) littermates were used. Male mice were injected by $\mathrm{N}$-diethylnitrosamine (DEN; $5 \mathrm{mg} / \mathrm{kg}$, single dose intraperitoneally, Sigma Aldrich, St Louis, MO, USA) at 4 weeks of age to induce HCC. Control mice were injected with the vehicle, only. The mice were then subjected for micro-CT scan and tissue harvest after 52 weeks. Tumor formation (size, location, and number of satellite lesions) were assessed by micro-CT using Fenestra LC as a contrast agent (Inveon, Siemens Health Care Global, Erlangen, Germany). The volumetric analysis was performed with the ASIPro VMsoftware (Concorde MicroSystems, Knoxville, TN, USA).

Five wt and four galectin $3^{-1-}$ mice were included in this study. All procedures were reviewed and approved by the Animal Care Committee of the University of California Davis.

\section{RNA Interference}

The immortalized mouse hepatoma cells Hepa1-6 (ATCC, Manassas, VA, USA) were cultured in DMEM supplemented with $10 \%$ fetal bovine serum. The cells were maintained at $37^{\circ} \mathrm{C}$ in $5 \% \mathrm{CO}_{2}$ until the cells were $80 \%$ confluent, and then used for transfection.

siRNA to galectin 3 (Santa Cruz Biotechnology, Santa Cruz, CA, USA), or negative control scrambled siRNA ( $25 \mathrm{nM}$, QIAGEN, Valencia, CA, USA) was transfected into Hepa1-6 with RiboJuice transfection reagent (Novagen, Madison, WI, USA), according to the manufacturer's instruction.

\section{cDNA Transfection}

Hepa1-6 cells were transfected with the pCMX-I $\kappa \mathrm{B} \alpha$ phosphorylation mutant (kindly provided by S Devaraj, Texas Children's Hospital, Houston, TX, USA), originally from Addgene, pCMX-IkB $\alpha$ developed by Dr Inder Verma, ${ }^{15}$ or the control vector (transfection efficiency, 60-70\%), using the GeneJuice Transfection reagent (Novagen), following the manufacturer's instruction.

\section{Chromatin Immunoprecipitation and Quantitative PCR Assay}

NF- $\kappa \mathrm{B}$ binding sites within mouse Gal3 promoter (+200 to 2000 bp) were identified by PROMO online (http://alggen.lsi. upc.es). Chromatin immunoprecipitation (ChIP) was carried out as described previously. ${ }^{16}$ After agarose gel electrophoresis and the product's size was confirmed with the average length 200-600 bp, rabbit anti-NF- $\kappa$ B (p65; Cell Signaling Technology, Beverly, MA) was used to pull down the transcription factor/DNA complex. Purified rabbit IgG (Santa Cruz Biotechnology) served as a control. Immunoprecipitated DNA was measured by quantitative PCR (qPCR) for the respective NF- $\kappa$ B binding sites using Power SYBR Green PCR master mix (Applied Biosystems, Foster City, CA, USA). Primers were designed using Genscript online tool (https:// www.genscript.com/ssl-bin/app/primer). A fragment (-205 to -137 ) adjacent to putative NF- $\kappa \mathrm{B}$ binding sites were amplified with primers: forward, 5'-GCAGGATGAGACCCT GACA-3', and reverse, 5'-GACCGCACCCAGACTCTC-3'. For $\mathrm{qPCR}$ results, the relative gene expression profile was achieved by normalizing the $\Delta \mathrm{Ct}$ of targets to the $\mathrm{Ct}$ of IgG ChIP of each sample. The data were presented as fold enrichment.

\section{Wound Closure Assay}

The scrambled or galectin 3 siRNA-transfected Hepal-6 cells were incubated in the presence or the absence of recombinant galectin $3(1 \mu \mathrm{M}$, provided by Dr F-T Liu, UC Davis). After $48 \mathrm{~h}$ of transfection, the cultures were scraped with a singleedged razor blade. Twenty-four hours later, five microscopic fields were evaluated, and the number of cells migrating across the wound edge were determined in each field and calculated for each injury. In non-treated cells, migration was also assessed in the presence of Y-27632 (ROCK inhibitor, $10 \mu \mathrm{M}$, Sigma, St Louis, MO, USA). The experiments were repeated three times.

\section{Immunohistochemistry and Immunofluorescence Microscopy}

The liver/tumor tissue was fixed in $4 \%$ buffered formalin and embedded in paraffin. H\&E and reticulin staining were conducted by the Department of Pathology, UC Davis. The histology was analyzed by a hepatopathologist in a blinded fashion.

To detect galectin 3 , the slides $(4 \mu \mathrm{m})$ were deparaffinized and rehydrated. For antigen retrieving, the slides were boiled in citrate buffer $(0.01 \mathrm{M}, \mathrm{pH}$ 6.0). After incubated in $3 \%$ aqueous $\mathrm{H}_{2} \mathrm{O}_{2}$ to ablate endogenous peroxidase, the sections were washed in $0.1 \%$ Triton X-100 and blocked with the reagents provided by the UltraVision Protein Block (Thermo Scientific, Rockford, IL, USA). Sections were then sequentially incubated with primary antibody (galectin 3, 1:1000, kindly provided by Dr F-T Liu, ${ }^{17}$ glypican 3, 1:100, Abcam, Cambridge, MA, USA), secondary HRP-conjugated antibody (1:500, Santa Cruz Biotechnology). The slides were then 
treated with DAB Substrates (Abcam) to visualize the signal and counterstained with Mayer's hematoxylin. The vascular invasion was quantified in five fields in each animal.

Human HCC sections were obtained from the Department of Pathology, UC Davis. Sequential sections were processed for $\mathrm{DAB}$ staining to detect galectin 3/glypican 3 , and galectin $3 / \mathrm{NF}-\kappa \mathrm{B}$ (p65) following the protocol described. NF- $\kappa \mathrm{B}$ (p65) antibody (1:200) was purchased from Cell signaling Technology.

Cryostat sections from the frozen liver/tumor tissue, in consecutive sections to those slides with $\mathrm{H} \& \mathrm{E}$ staining were co-stained with anti-galectin 3 and F4/80 antibodies (1:200, eBioscience, San Diego, CA, USA) followed by fluorescencelabeled secondary antibodies (Life Technology). The images were analyzed by fluorescent microscopy to assess the colocalization of galectin 3 and $\mathrm{F} 4 / 80$. The galectin $3^{+} / \mathrm{F} 4 / 80^{+}$ cells were counted from five random views each slides. The cryostat sections were also probed with e-cadherin (1:500, BD Biosciences, San Jose, CA, USA) to analyze the cell migratory activity. To assess the cell proliferation and apoptosis, Ki67 (Abcam) and active caspase-3 (1:500, Cell Signaling Technology) staining were performed. The positive cells in five fields were counted for each mouse.

To detect the cellular localization of RhoA, Hepa1-6 cells were transfected with scrambled or galectin 3 siRNA, fixed with $4 \%$ paraformaldehyde and permeabilized in $0.2 \%$ Triton X-100/PBS. After washing, they were blocked with $2 \%$ bovine serum albumin followed by incubating with anti-RhoA monoclonal antibody (1:40, Santa Cruz Biotechnology) for $16 \mathrm{~h}$ at $4{ }^{\circ} \mathrm{C}$. The slides were then washed and incubated with rhodamine-conjugated phalloidin to visualize F-actin filaments. After washing, the secondary Alex Fluor 488-labeled anti-mouse IgG (1:1000, Life Technologies, Carlsbad, CA, USA) was applied. The images were analyzed by fluorescence microscopy.

Hepa1-6 cells transfected with scrambled or galectin 3 siRNA were treated with fas ligand (FSL; $5 \mathrm{ng} / \mathrm{ml}, 16 \mathrm{~h}$, Millipore, Billerica, MA, USA), and stained for active caspase 3. The cell proliferation was evaluated by Ki67 staining.

\section{RNA Extraction and Real-Time RT-PCR}

RNA was extracted from the cells or tissues using RNeasy Mini kit (QIAGEN) following the manufacturer's instruction. cDNA was synthesized using the iScript cDNA Synthesis kit (Bio-Rad, Hercules, CA, USA). The SYBR Green DNA Master mix (Applied Biosystems) was used for real-time PCR analysis (Life Technologies). The galectin-3 primers used were described previously. ${ }^{8}$ For e-cadherin, the forward primer

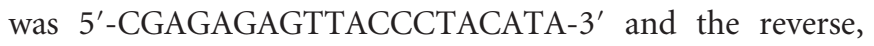
5'-GTGTTGGGGGCATCATCATC-3'; for vimentin, forward, 5'-GCACCCTGCAGTCATTCAGA-3' and reverse, 5'-CCAC TTTCCGTTCAAGGTCAAG-3' .

\section{Rho Activation, Pull-Down Assay}

Tumor tissue or siRNA-transfected Hepa1-6 cells were lyzed and the supernatant was collected for the pull-down assay using a Rho activation assay kit (Millipore). In brief, the cell lysates containing $1 \mathrm{mg}$ protein were mixed with glutathioneagarose beads bound with Rhotekin, containing a GTP-Rhobinding domain. After incubation, the agarose beads were washed and collected by centrifugation, then resuspended in the sample buffer containing $1 \mathrm{M}$ dithiothreitol. The active GTP-Rho was released and denatured by boiling. The supernatant was collected and separated by SDS-polyacrylamide gel (PAGE). The GTP-bound RhoA was detected by the antibody provided by the kit.

\section{Western Blot Analysis}

Benign liver and tumor tissue was homogenized in RIPA buffer with protease inhibitor cocktails. The protein concentration was determined with the Bio-Rad protein assay kit (Thermo Scientific) and $20 \mu \mathrm{g}$ of protein was separated by SDS-PAGE. The blot was probed with anti-galectin3 (kindly provided by Dr F-T Liu, UC Davis) and anti-GAPDH (Trevigen, Gaithersburg, MD, USA) as internal control. Hepa1-6 cells were transfected with scrambled or galectin 3 siRNA, as above. Fifty micrograms of protein was used for western blot. The blots were incubated with the appropriate antibodies for $16 \mathrm{~h}$ at $4{ }^{\circ} \mathrm{C}$ : anti-phospo-NF- $\kappa \mathrm{B}$ (p65; Cell Signaling Technology), phospho MLC2 and MLC2 antibodies (Cell Signaling Technology), phospho-Akt and total Akt antibodies (Cell Signaling Technology) or the anti-galectin 3 antibody. The membranes were incubated with horseradish peroxidase-conjugated secondary antibodies (Santa Cruz Biotechnology) and the blots were developed by enhanced chemiluminescence (Thermo Scientific). The intensity of signals was quantified with ImageJ (National Institutes of Health, Bethesda, MD, USA). The data were normalized to the expression of anti-GAPDH antibody.

\section{Statistical Analysis}

The data shown represent at least three experiments and expressed as the mean \pm s.e.m. Differences between groups were compared using one-way analysis of variance associated with the Dunnett's test. Statistical significance was considered when $P<0.05$.

\section{RESULTS}

\section{Galectin $3^{-/-}$Mice have a Decreased Tumor Burden and a Less Invasive Phenotype of HCC}

To study the role of galectin 3 in an in vivo model of HCC, the wt and galectin $3^{-/-}$mice were injected with DEN or corn oil at the age of 4 weeks to induce HCC. Micro-CT scans were performed after 52 weeks to assess tumor size by volumetric analysis. (Figure 1aA-D). Although in the wt mice the livers were largely replaced by tumors, the tumor burden in the galectin $3^{-1-}$ mice was significantly reduced $\left({ }^{*} P<0.01\right.$, Figure 1b). The liver tissues were harvested and processed for 
a
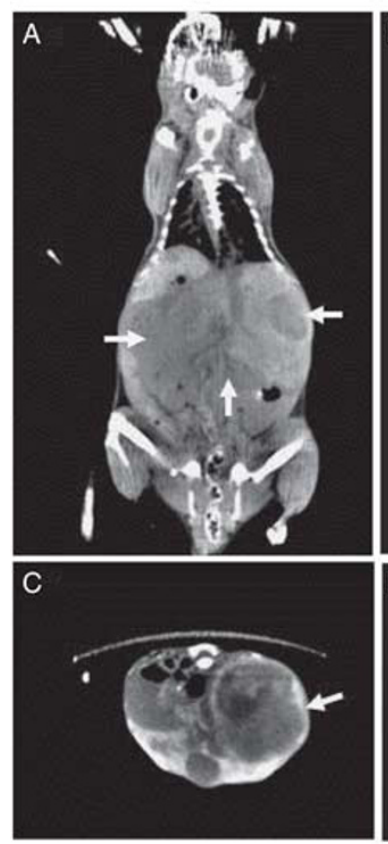

b

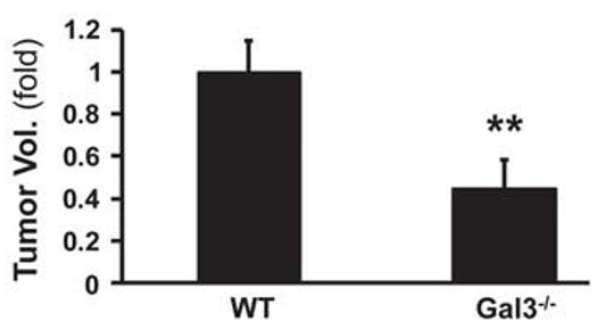

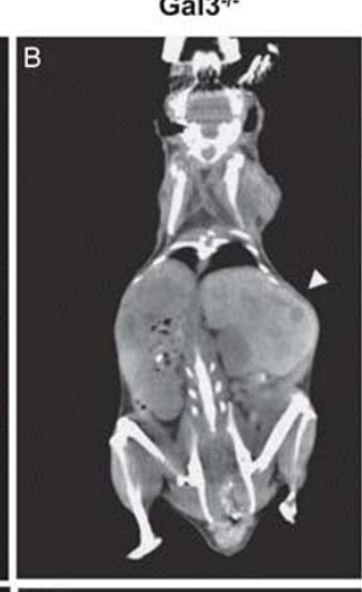

c

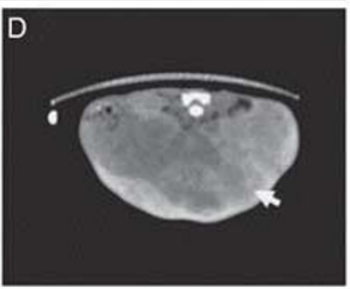

\section{I}
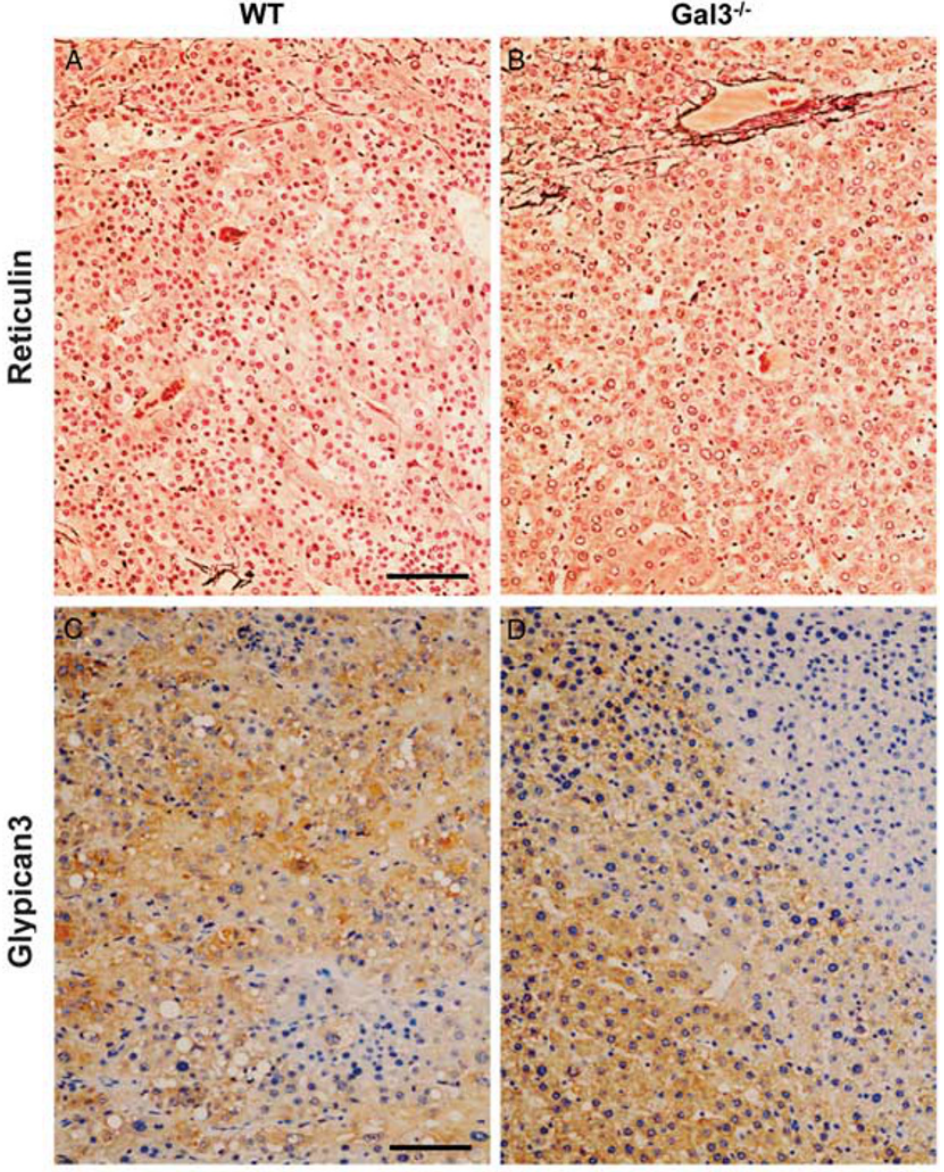

Figure 1 Galectin $3^{-/-}$mice exhibit decreased tumor burden compared with the wild-type mice. Wild-type and galectin $3^{-/-}$mice were injected with $\mathrm{N}$-diethylnitrosamine at 4 weeks of age to induce hepatocellular carcinoma (HCC). After 52 weeks, the mice were injected via tail vein with $200 \mu$ l of the contrast agent Fenestra LC and subjected to Micro-CT scan. The tumor size was assessed by volumetric analysis (a). The HCC on the CT is depicted as large hypodense areas (arrows) in the wild-type mouse, (coronal view, A; and horizontal view, C). In the galectin3 ${ }^{-\prime-}$ mice smaller tumors were seen ( $B$ and $D$, arrowhead). By volumetric analysis, in the galectin $3^{-/-}$mice the tumor burden was significantly lower (b, $\left.{ }^{* *} P<0.01, N=5\right)$. The liver tissues from these mice were processed for immunohistochemistry to detect reticulin (c, A and B) and glypican 3 (c, C and D). Both wt and galectin $3^{-/-}$livers showed reduced reticulin and they were positive for glypican 3 . This confirmed the presence of HCC in the mice. Bar $=100 \mu \mathrm{m}$.

reticulin staining and glypican 3 immunohistochemistry staining to confirm the presence of HCC (Figure 1c). Both wt and galectin $3^{-1-}$ mice remarkably lost reticulin stains in the tumor area (Figure 1cA, B). They both were positive for another HCC marker glypican 3 (Figure 1cC, D).

On the basis of the histological analysis (Figure 2a), HCC from the wt mice exhibited more invasive properties with spindle-like cells and frequent vascular invasion (arrows). The tumors from the galectin $3^{-1-}$ mice exhibited a more differentiated, glandular phenotype, with histologically normal areas (nl) with portal tracts present. The vascular invasion foci were counted in five fields each animal (Figure 2b). Significantly less vascular invasion was observed in the galectin $3^{-/-}$livers. The mRNA levels of e-cadherin and vimentin were assessed to further evaluate the invasive properties in these tumor tissues (Figure $2 \mathrm{c}$ and $\mathrm{d}$ ). Wt tumors expressed significant lower level of e-cadherin $\left({ }^{\star} P<0.05\right)$ and higher level of vimentin, suggesting an invasive phenotype compared with the knockout tumors. The e-cadherin immunofluorescent staining also showed reduced e-cadherin in the wt tumor (Figure $2 \mathrm{e}$ ).

Fluorescent staining was also performed to detect Ki67 and active caspase 3 to assess the cell proliferation and apoptosis (Figure 2f). The positive cells were quantified as described. The wt tumor showed higher proliferation activity and lower apoptosis.

\section{Galectin 3 is Upregulated in HCC Tumor Cells and Tumor-Associated Macrophages}

Next we examined the expression of galectin 3 in HCC. Sequential sections from human HCC were stained with galectin 3 and HCC marker glypican 3 (Figure 3a). The galectin 3 positive areas were highly identical with the glypican 3 positive areas, indicating the correlation of 
a

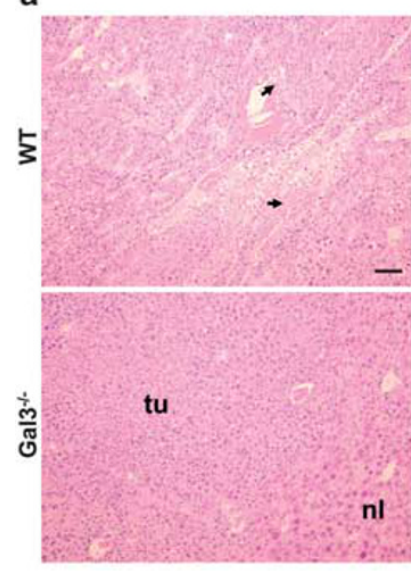

e

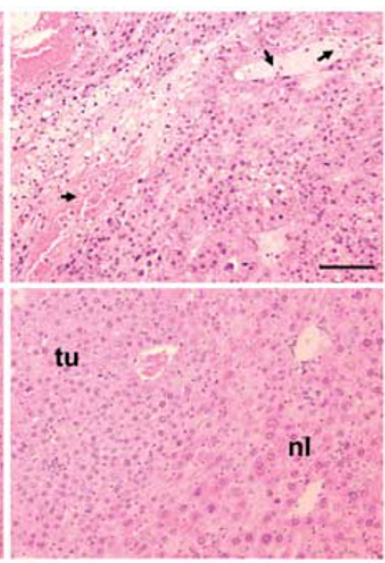

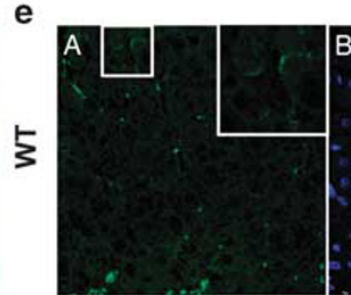
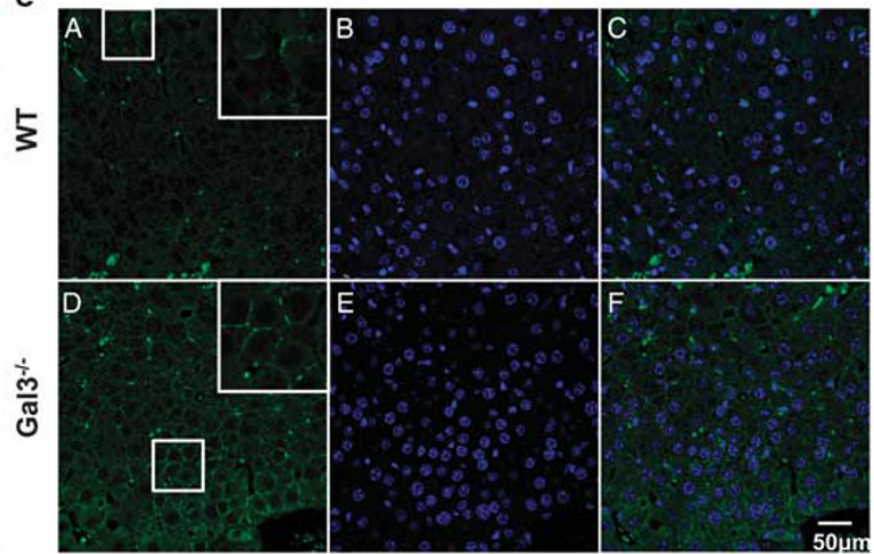

f
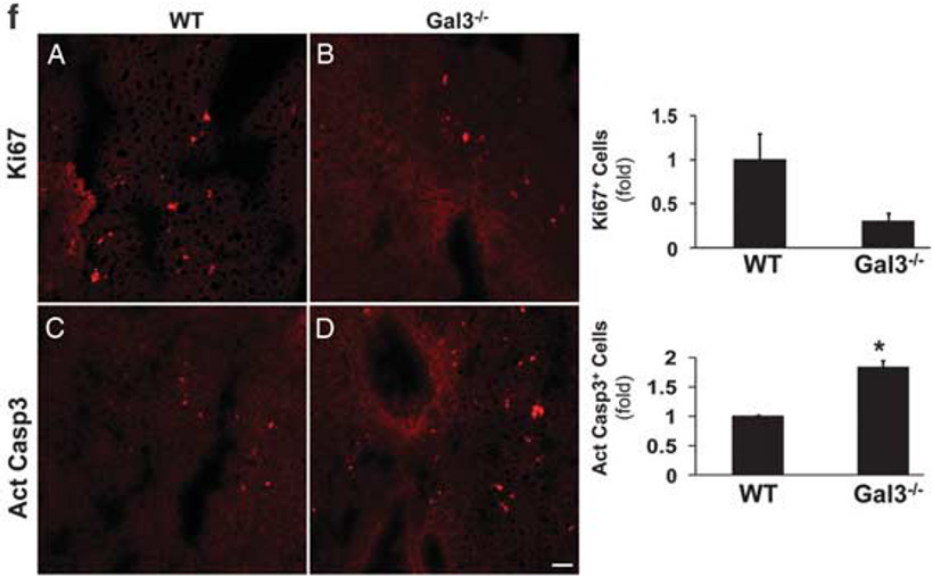

Figure 2 Galectin $3^{-/-}$tumors show less invasive phenotype. Liver sections from the N-diethylnitrosamine-injected wild-type and galectin $3^{-/-}$mice were stained by H\&E (a). Hepatocellular carcinoma from the wild-type (wt) mice exhibited more invasive properties with spindle-shaped cells whereas tumors from galectin $3^{-1-}$ mice had a more differentiated phenotype (nl-normal, tu-tumor tissue). Vascular invasion was observed in wt tumors (arrows). $\mathrm{Bar}=100 \mu \mathrm{m}$. The foci of vascular invasion were counted in five fields from each animal (b). The wt mice showed significant more foci compared with the knockout mice $\left({ }^{* *} P<0.01, N=4\right)$. RT-PCR was conducted to measure the mRNA of e-cadherin and vimentin (c and $\left.\mathbf{d}\right)$. The wt tumors expressed a significant higher level of e-cadherin $\left({ }^{*} P<0.05, N=4\right)$ and a lower level of vimentin, suggesting a high invasive phenotype compared with the galectin $3^{-/-}$tumors. Immunofluorescent staining was done on the frozen sections to detect e-cadherin (e). Consistent with the PCR data, the wt tumor showed lower expression of e-cadherin. Bar $=50 \mu \mathrm{m}$. The frozen sections were also stained for Ki67 and active caspase 3 (f). The positive cells were counted in five fields from each animal. The wt tumors showed more Ki $67^{+}$cells and less active caspase $3^{+}$cells $(* P<0.05)$.

galectin 3 and HCC. In mice (Figure 3b), galectin 3 was highly expressed in the DEN tumor, mainly in hepatoma cells; macrophages were positive as well (Figure $3 \mathrm{bD}$, arrows). No galectin 3 signal was seen in normal hepatocytes (bA). The induction of galectin 3 in HCC was then confirmed with western blot analysis using benign and resected tumor tissues from the wt DEN mice (Figure $3 \mathrm{c}$ and d). The expression of galectin 3 was significantly higher in tumors than that in the surrounding parenchyma $\left({ }^{* *} P<0.001\right)$. As tumor-associated macrophages were shown to express galectin 3 , consecutive sections were processed for $\mathrm{H} \& \mathrm{E}$ and immunofluorescent staining with galectin 3 and the macrophage marker F4/80 (Figure 3f). Beside the increased galectin 3 expression in the tumor cells, there were a significantly higher number of macrophages co-expressing galectin 3 and F4/80 (Figure 3f,
gB-G, arrowhead) in the tumor tissues compared with the surrounding stroma $\left({ }^{\star \star} P<0.01\right)$.

\section{Galectin 3 Induction in Hepatoma Cells is Mediated by NF-KB Activation}

To study the mechanism of galectin 3 upregulation in hepatoma cells, we focused on NF- $\kappa \mathrm{B}$, as the induction of $\mathrm{NF}-\kappa \mathrm{B}$ is a key event to the pathogenesis of $\mathrm{HCC}^{18}$ and the promoter area of galectin 3 has been described to have NF- $\kappa B$-responsive elements. ${ }^{8,19,20}$ Sequential sections from human HCC were stained for galectin 3 and NF- $\kappa \mathrm{B}$ (p65; Figure $4 \mathrm{a})$. The nuclear staining of p65 was observed in galectin 3 positive cells, suggesting the correlation of the activation of NF- $\kappa \mathrm{B}$ signaling and galectin 3 expression in HCC. Next, tumor tissues and adjacent benign tissue from 
DEN-treated wt mice were processed for ChIP-qPCR assay to assess the transcriptional regulation of NF- $\kappa \mathrm{B}$ on the galectin 3 promoter. The transactivation of NF- $\kappa \mathrm{B}$ within the mouse galectin 3 promoter was significantly induced in the tumor tissues (Figure $4 \mathrm{~b},{ }^{\star} P<0.05$ ). To corroborate our in vivo data we transfected Hepal- 6 cells with the pCMX-I $\kappa \mathrm{B} \alpha$ (phosphorylation mutant) vector to block the NF- $\kappa \mathrm{B}$ signaling cascade, or a control vector. The PCR data showed that the galectin 3 expression decreased in the pCMX-I $\kappa \mathrm{B} \alpha$-transfected cells (Figure $4 \mathrm{c},{ }^{* *} \mathrm{P}<0.001$ ), suggesting that NF-kB has an important role in galectin 3 induction in HCC carcinogenesis. To compare the activation of NF- $\kappa \mathrm{B}$ in wt and galectin $3^{-1-}$ tumors, the tissues were homogenized for western blots to detect phospho-p65 (Figure 4d and e). The phospho-65 level was significantly less in the knockout tumors $\left({ }^{\star} P<0.05\right)$.

\section{Galectin 3 Induces the Migration of HCC Cells}

Because of the observed histological differences, and the smaller tumor burden in the galectin $3^{-/-}$mice we postulated a
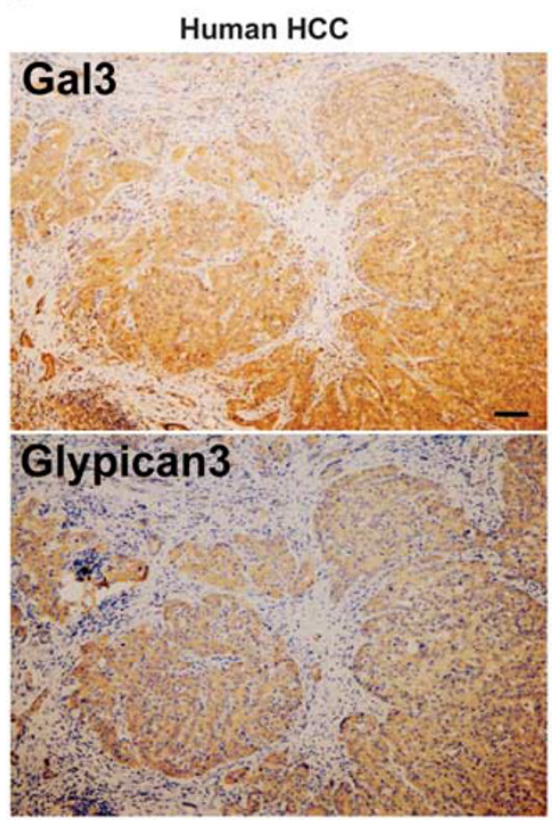

b
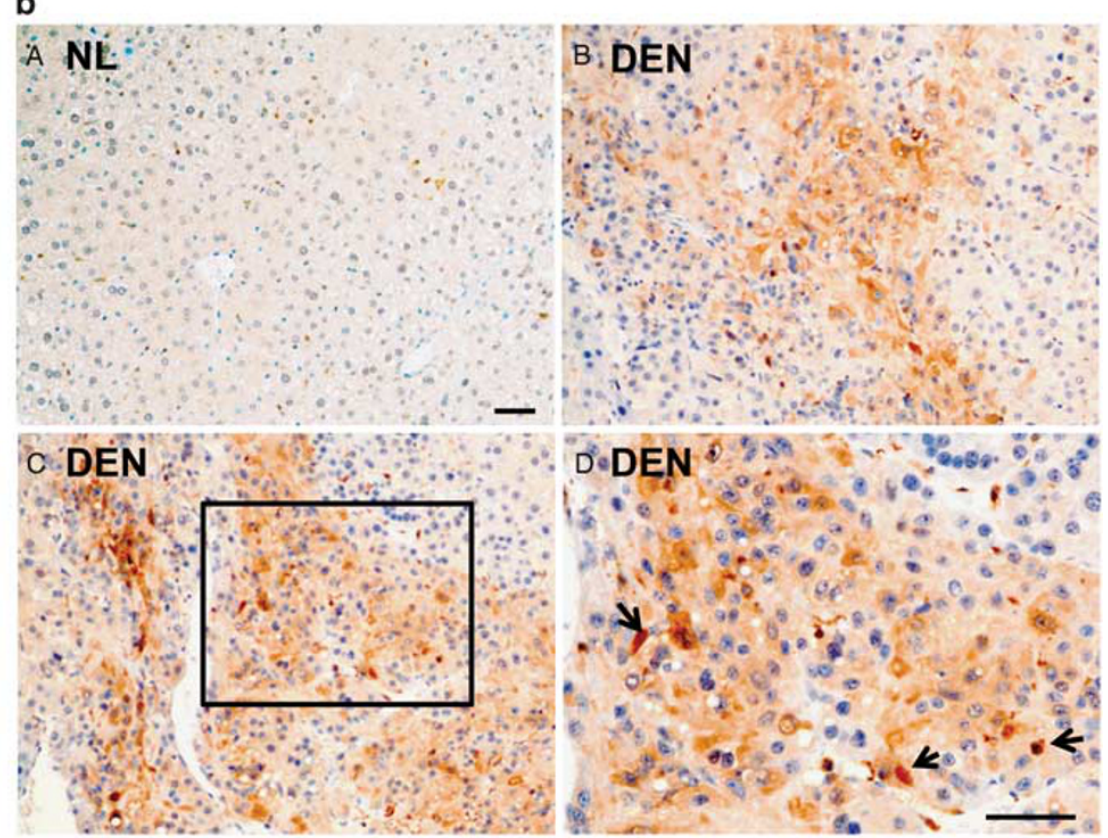

C
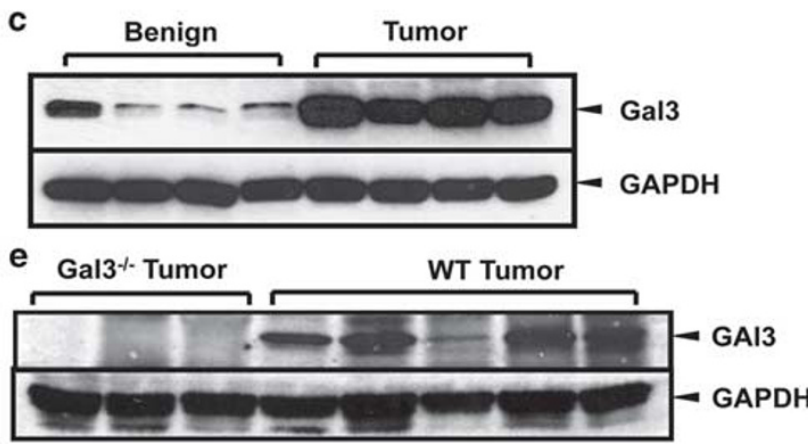

d

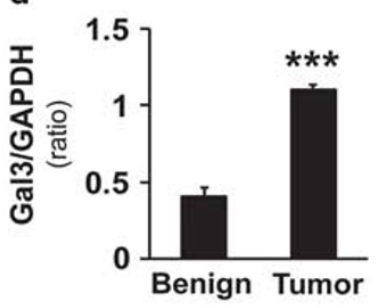

Figure 3 Galectin 3 is upregulated in hepatocellular carcinoma (HCC) tumor cells and tumor-associated macrophages. Sequential sections from human HCC patients were used for immunohistochemistry staining targeting galectin 3 and glypican 3 (a). The image showed that the galectin 3 positive areas were highly identical with the glypican 3 positive areas in human HCC. The immunohistochemistry staining for galectin 3 was then conducted in the tissues from normal (NL) and wild-type (wt) N-diethylnitrosamine (DEN)-treated mice (b). Galectin 3 was highly expressed in DEN induced tumors (B-D), mainly in hepatoma cells. The high magnification image (bD) depicted tumor-associated macrophages also expressing galectin 3 (arrow). Normal hepatocytes in control liver did not express galectin $3(\mathbf{b A})$. Western blot analysis and ImageJ quantification showed that galectin 3 expression was significantly higher in the tumor tissues ( $\mathbf{c}$ and $\mathbf{d} ; N=4,{ }^{* * *} P<0.001$ ). Western blot assay was also conducted on the wt and galectin $3^{-1-}$ tumors for antibody validation (e). No bands were detected in $\sim 30 \mathrm{kDa}$ area in the knockout tumors and strong signals were shown in the wt tumors. Immunofluorescence and confocal microscopy on consecutive sections to the H\&E-stained sections was performed to assess galectin 3 (red) and F4/80 (marker for tumor-associated macrophages TAM, green, $\mathbf{f}$ ). Analyzing the areas of HCC bordering the surrounding parenchyma, clusters of TAM co-expressed galectin 3 and F4/80 (B-D, arrowhead, Bar $=50 \mu \mathrm{m}$ ) whereas no expression was seen in the normal hepatocytes and F4/80 positive cells were rare in the normal tissue $(\mathrm{E}-\mathrm{G})$. The tumor tissue carried a significant higher number of galectin $3^{+} / \mathrm{F} 4 / 80^{+}$cells $\left(\mathbf{g},{ }^{* *} P<0.01\right)$. 

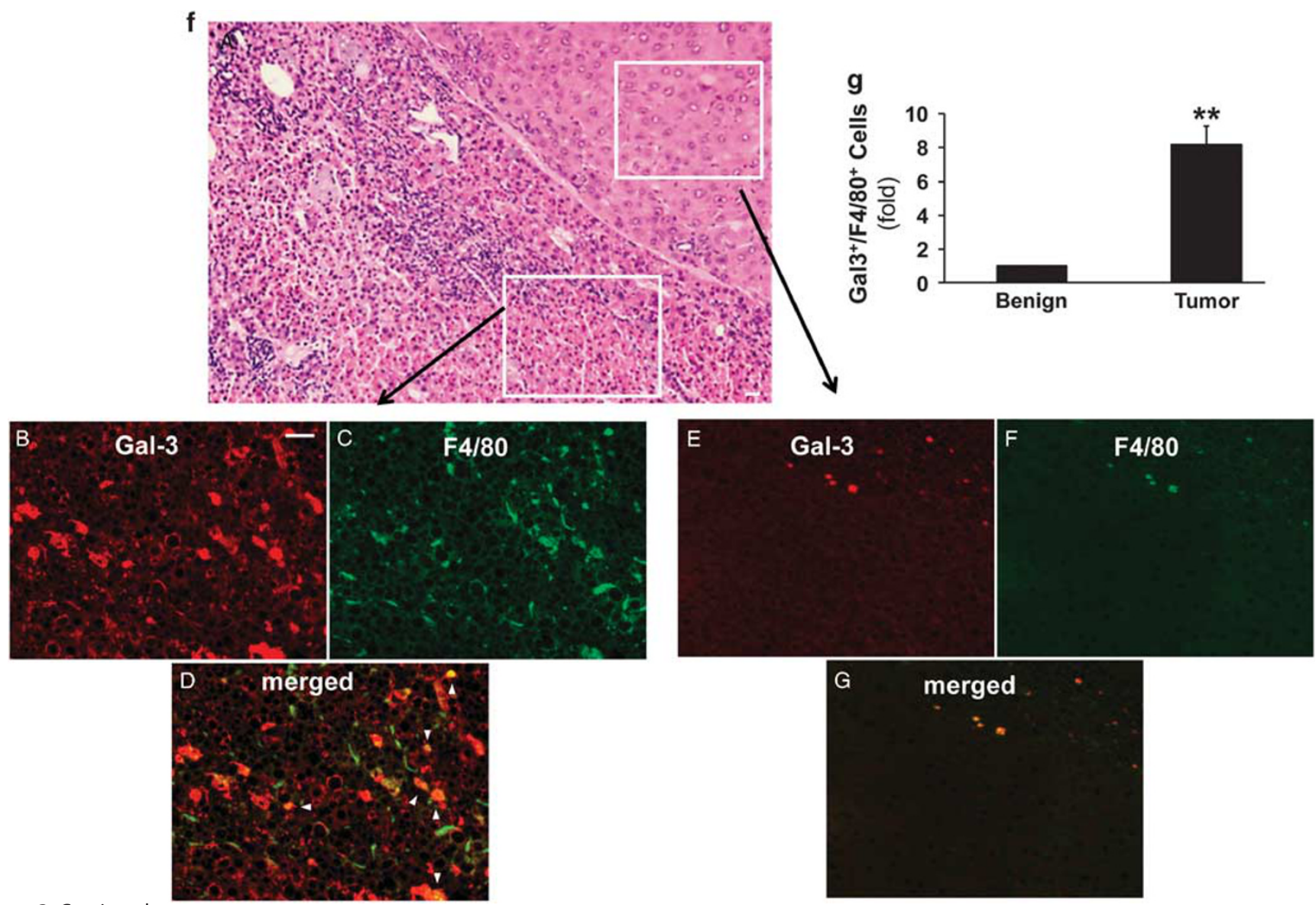

Figure 3 Continued.

that galectin 3 modulates the invasive properties of HCC cells. Hepa1-6 cells were transfected with scrambled or galectin 3 siRNA, and scratch assay was performed. The galectin 3 siRNA-transfected cells showed a significantly lower migratory activity compared with the cells transfected with scrambled siRNA (Figure $4 \mathrm{a}$ and $\mathrm{b},{ }^{*} P<0.01$ ). The inhibition of migration was partially reversed by recombinant galectin 3 (Figure $4 \mathrm{aD}$, and $\mathrm{b},{ }^{* *} P<0.001$ ), suggesting that extracellular galectin 3 is also involved in regulating HCC cell motility.

We also examined the proliferation and apoptosis rate of these cells (Figure 5c-e). The hepal-6 cells expressing scrambled or galectin 3 siRNA were stained for Ki67. To evaluate the apoptosis, these cells were treated with FSL before the staining for active caspase 3 . The Ki67 ${ }^{+}$cells were significantly reduced by galectin 3 siRNA $\left({ }^{*} P<0.05\right)$; and the active caspase $3^{+}$cells were increased by galectin 3 silencing $\left({ }^{*} P<0.01\right)$. This confirmed our in vivo data that galectin 3 deficiency impaired cell proliferation and promoted apoptosis in mouse HCC (Figure 2f).

As cytoskeletal remodeling is crucial in cell migration, next we focused on the galectin 3-mediated regulation and recruitment of the RhoA GTPase to the leading edge, and the reorganization of the actin cytoskeleton. Hepal-6 cells were transfected with scrambled or galectin 3 siRNA, and immunofluorescence microscopy was done to visualize F-actin filaments and RhoA (Figure 6a). The galectin 3 siRNA-transfected cells exhibited different morphology with a more rounded phenotype, whereas the non-transfected or scrambled siRNA transfected cells had elongated, fusiform morphology. RhoA and F-actin were co-localized to the leading edge in the non-transfected and scrambled siRNAtransfected cells (arrows). In contrast, these signals were cytoplasmic in the cells expressing the galectin 3 siRNA. To study RhoA activation, a pull-down assay was done to assess the GTP-bound RhoA in galectin 3 or scrambled siRNAtransfected cells. RhoA GTPase activation was decreased after transfection with the galectin 3 siRNA (Figure $6 \mathrm{~b}$ and $\mathrm{c}$, $\left.{ }^{*} P<0.05\right)$. The RhoA activation was also examined in vivo. The wt and the galectin $3^{-1-}$ tumor tissues were processed for the pull-down assay (Figure $6 \mathrm{~d}$ and e). The galectin $3^{-1-}$ tumors showed a lower level of active RhoA.

\section{HCC Cell Migration is Rho-Kinase and MLCK Mediated}

Because ROCK is a downstream effector of RhoA in the regulation of cytoskeletal reorganization and cell motility, Hepa1-6 cells were incubated with Y-27632 (ROCK inhibitor), and migration was assessed by a wound closure assay. 
a

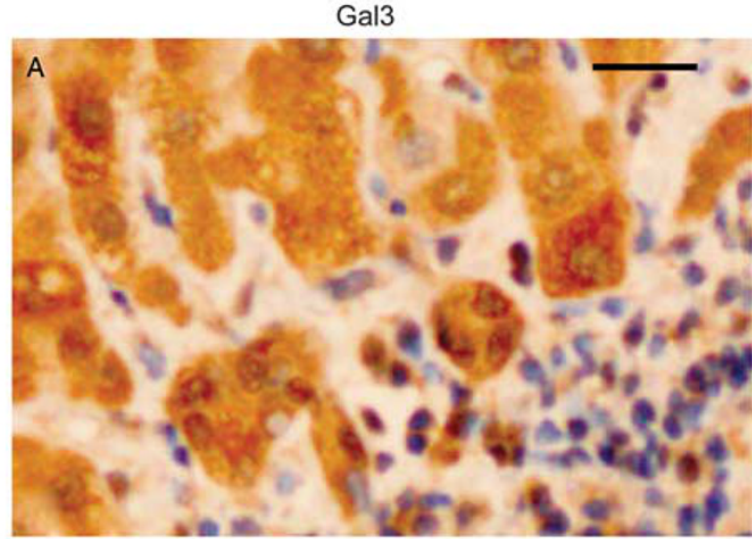

p65

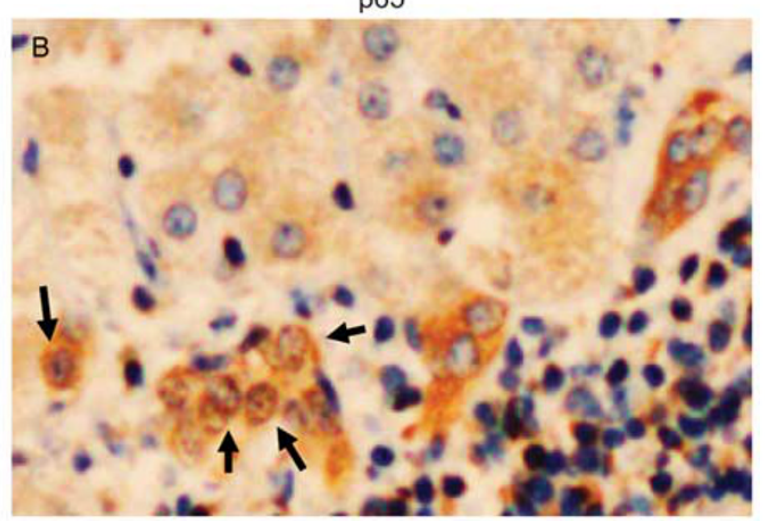

Human HCC
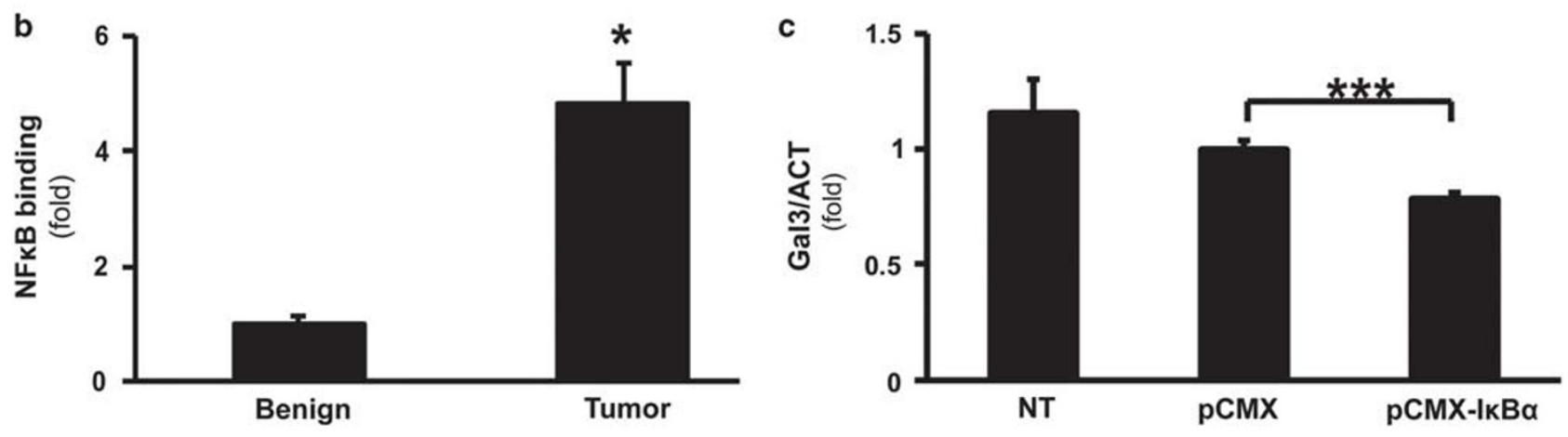

d

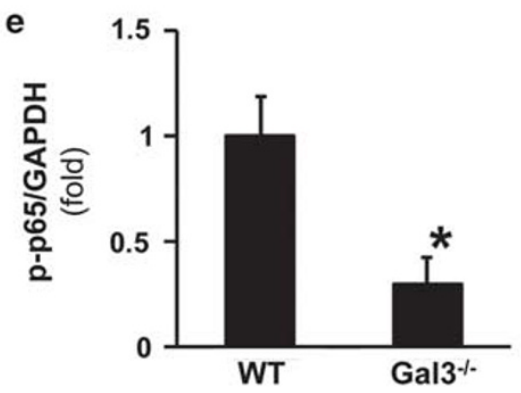

Figure 4 Galectin 3 expression in hepatocellular carcinoma (HCC) is induced by NF- $\mathrm{KB}$ transactivation. Consecutive sections from human HCC were stained for galectin 3 and NF-kB (p65) (a). The nuclear translocation (B, arrows) was observed in galectin 3 positive cells (Bar $=50 \mu \mathrm{m})$. Chromatin immunoprecipitation assay was performed on benign tissue and $\mathrm{N}$-diethylnitrosamine-induced tumors in wild-type mice (b). The NF- $\mathrm{KB}$-induced transactivation of the Gal3 promoter was significantly induced in the tumor tissues compared with the benign controls $\left(N=4,{ }^{*} P<0.05\right)$. Hepa1-6 cells were transfected with the pCMX-IkBa (phosphorylation mutant blocking the nuclear translocation of NF-kB) or the control vectors (c). RT-PCR showed that galectin 3 expression decreased in the $\mathrm{pCMX-IKB}$-expressing cells (mean \pm s.e.m., $N=3,{ }^{* * *} P<0.001$ ). The NF- $K B$ phosphorylation was examined in wt and galectin $3^{-1-}$ tumors by western blots ( $\mathbf{d}$ and $\left.\mathbf{e}\right)$ Less phospho-NF-KB was detected in the knockout tumors $\left({ }^{*} P<0.05\right)$.

The cell migration was significantly inhibited by Y-27632 (Figure $7 \mathrm{a}$ and $\mathrm{b},{ }^{\star} P<0.05$ ). The contraction of the actin cytoskeleton through activation of myosin 2 is essential in exerting force to induce the cells motility. ${ }^{21}$ The actin-myosin 2 interaction is regulated by the phosphorylation of MLC2 on Ser-19.22 The regulatory MLC2 are known to be phosphorylated by the myosin light chain kinase (MLCK) as a downstream target of ROCK. ${ }^{22}$ We found that in the galectin 3 siRNA-transfected Hepal-6 cells, corresponding to the decrease in RhoA and ROCK activity; the phosphorylation of MLC2 was significantly reduced (Figure $7 \mathrm{c}$ and $\mathrm{d}$, $\left.{ }^{*} P<0.05\right)$.

\section{DISCUSSION}

Tumor cell migration and locoregional invasion are characteristic features of HCC spread, and because of the lack of satisfactory treatment options, these histological findings herald a poor prognosis. Because the remodeling of the cytoskeleton is crucial in cell migration, and the Rho family of small GTPases are known to regulate the actin 
a
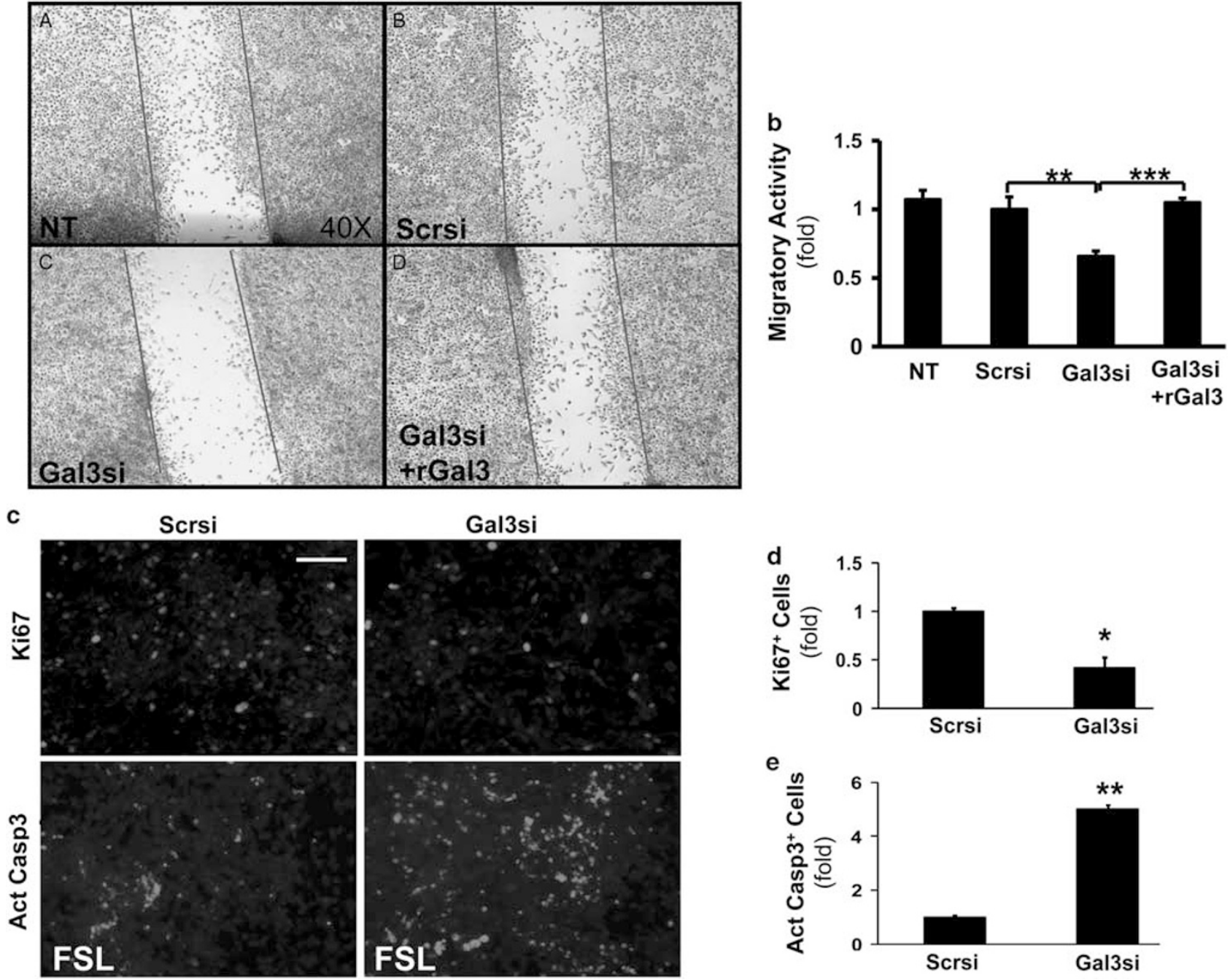

Figure 5 Galectin 3 mediates the migratory activity of hepatoma cells. To analyze the effect of galectin 3 on cell migration, Hepa1-6 cells were transfected with either scrambled (Scrsi) or galectin 3 siRNA (Gal3si), and $48 \mathrm{~h}$ later wound closure assay was performed (a and b). Non-transfected (NT) cells were used as a control. After $24 \mathrm{~h}$, the number of migrating cells significantly decreased following galectin 3 siRNA transfection $(N=9$, ** $P<0.01)$ compared to the scrambled siRNA transfected cells. This was reversed by exposing the cells to recombinant galectin $3(1 \mu \mathrm{M}$ for $24 \mathrm{~h})$, suggesting the role of extracellular galectin 3 in the regulation of hepatocellular carcinoma cell migration. $\left({ }^{* * *} P<0.001\right)$. The above siRNA expressing cells were processed for fluorescent staining to detect Ki67 (c and d). The galectin 3 siRNA significantly reduced the number of Ki67 $7^{+}$cells $\left({ }^{*} P<0.05, N=4\right)$. To evaluate apoptosis, the above cells were incubated with FSL $(5 \mathrm{ng} / \mathrm{ml}, 16 \mathrm{~h})$, then stained for active caspase 3 (c and e). The galectin 3 siRNA significantly increased the number of active caspase $3^{+}$cells $\left({ }^{* *} P<0.01, N=4\right)$.

cytoskeleton, ${ }^{23,24}$ we have postulated that galectin 3 regulates and enhances RhoA activity in HCC tumor cells. Galectin 3 has been described to trigger signaling cascades by crosslinking with the glycan parts of the glycoconjugates, ${ }^{25}$ and we and others have shown that by binding to integrins it could elicit downstream signals affecting cytoskeletal reorganization and phagocytosis in hepatic stellate cells. ${ }^{8,12}$ In the current study we sought to understand the mechanism by which galectin 3 controls tumor cell motility. We found that RhoA GTPase activation and downstream ROCK and MLC2 phosphorylation leading to actin reorganization were dependent on galectin 3. RhoA/ROCK activation were described earlier as correlating to the locoregional invasion of human HCC, ${ }^{26}$ however the upstream regulators or cellular targets have not been fully evaluated. Discovering galectin 3 as a proximal inducer of the RhoA/ROCK pathway therefore could lead to novel therapeutic strategies. Targeting galectin 3 production or interfering with its ability to bind to the lattice could result in a less invasive phenotype, and a prolonged survival. ${ }^{27,28}$

Whether the intra-or extra-cellular galectin 3 has a more dominant role in regulating cell motility is also an important question. In this study we mainly focused on the mechanistic aspects by which intracellular galectin 3 modulates 
a
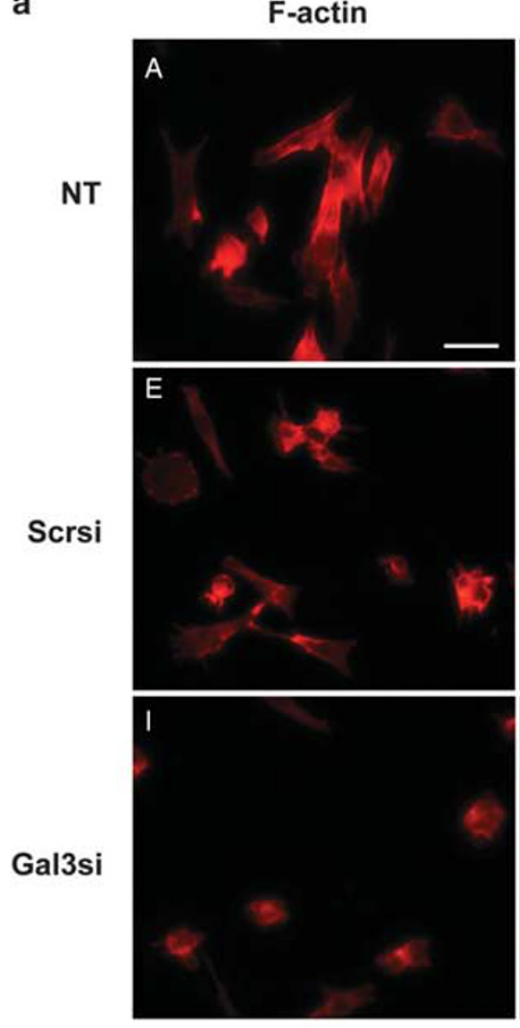

b

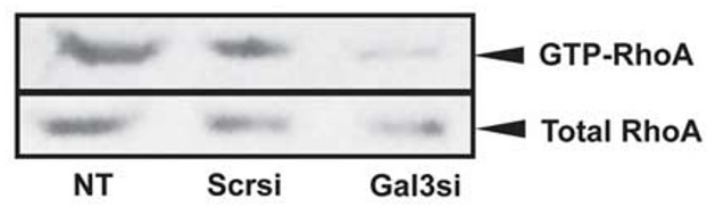

d

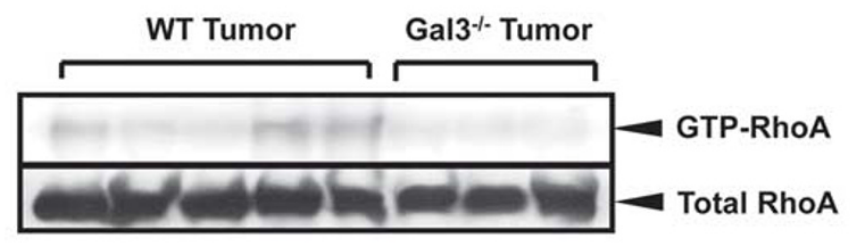

RhoA
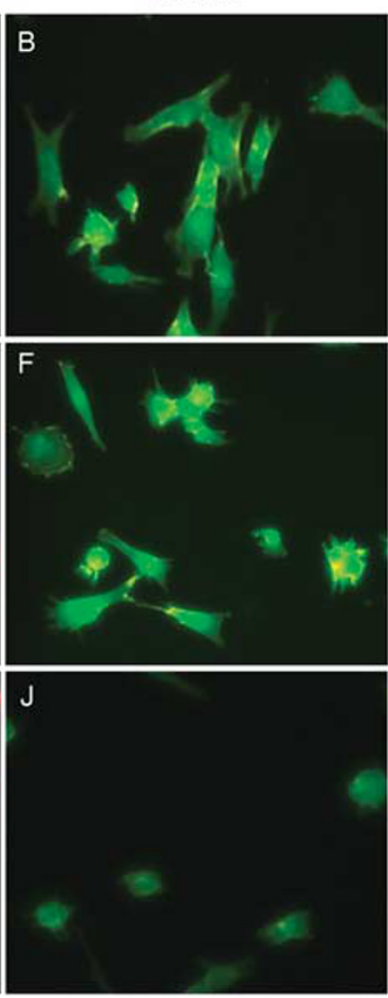

Gal3si
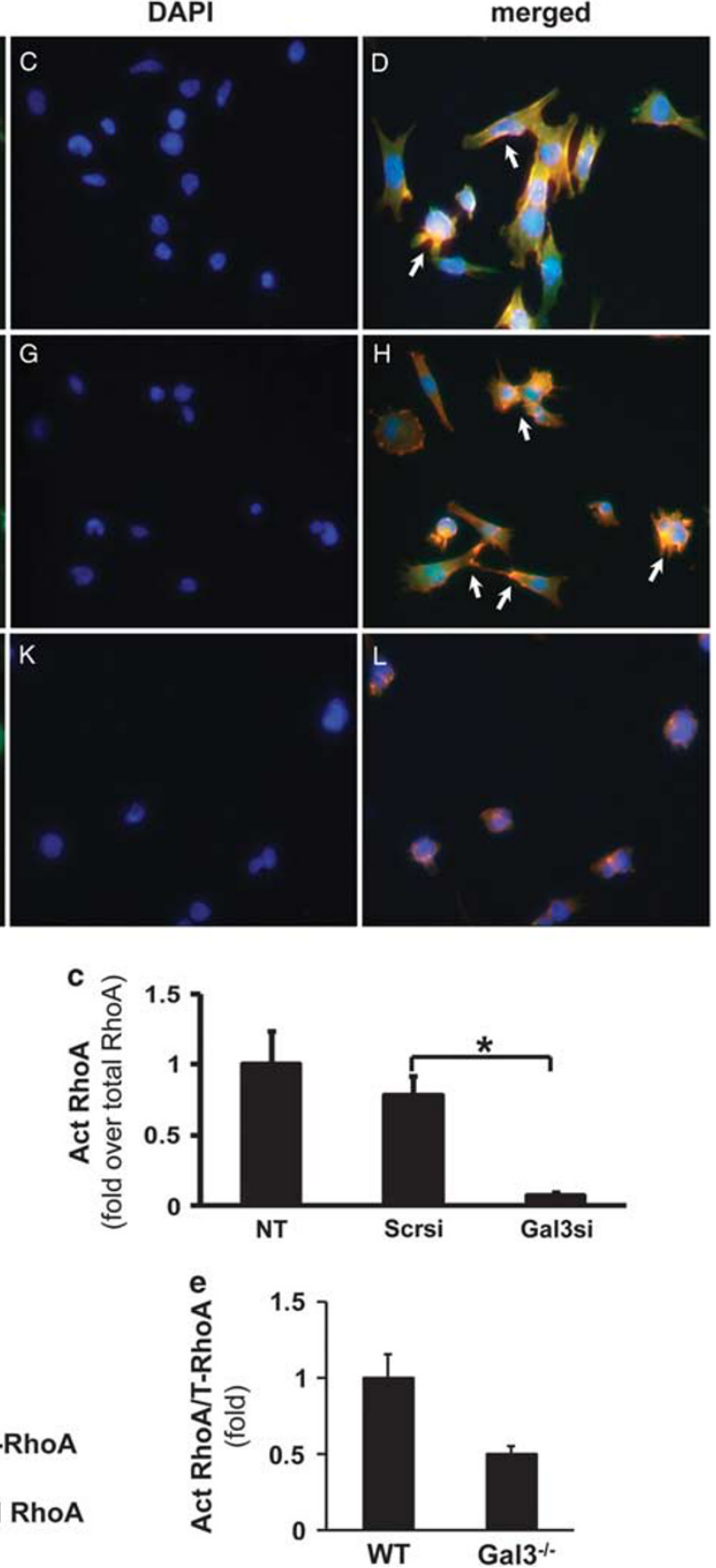

Figure 6 Galectin 3 inhibition results in the decrease in RhoA GTPase activity and actin reorganization in hepatocellular carcinoma cells. Hepa1-6 cells were transfected with either scrambled or galectin 3 siRNA. RhoA GTPase activity was assessed by pull-down of the GTP-RhoA in non-transfected (NT), scrambled or galectin 3 siRNA-transfected cells. RhoA activation was significantly decreased after galectin 3 siRNA transfection (b and c, mean \pm s.e.m., $\left.N=4,{ }^{*} P<0.05\right)$. The RhoA activation was examined in wt and galectin $3^{-1-}$ tumors as well ( $\mathbf{d}$ and $\mathbf{e}$ ). Less active RhoA was seen in the knockout tumors. Immunofluorescence staining was performed to assess RhoA (a: B, F, J, green) localization and phalloidin (a: A, E, I, red) to visualize F-actin filaments. RhoA/F-actin was localized to the leading edges in the NT and scrambled siRNA transfected cells (arrows). The galectin 3 siRNA-transfected cells had a more rounded shape with no lamellipodia formation and the RhoA staining was mainly cytoplasmic $(B a r=20 \mu \mathrm{m})$.

invasiveness. Our data suggest that galectin 3 affects tumor cell migration by an autocrine process, as we found that galectin 3 was significantly induced in HCC cells, and siRNA targeting decreased the migratory activity. Nevertheless our data also suggest that galectin 3 produced in a paracrine manner likely by tumor-associated macrophages can stimulate hepatoma cell motility possibly by affecting galectin $3 /$ integrin crosslinking. The dominant cell type corresponding to the major source of galectin 3 production in HCC could be further studied in the future in cell specific knockout mice. 

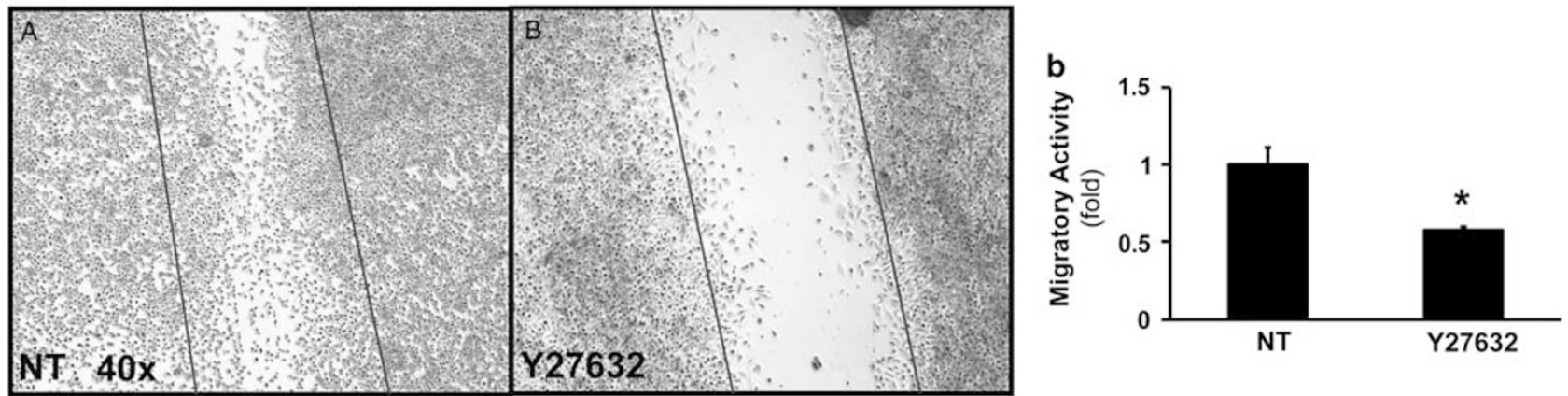

C
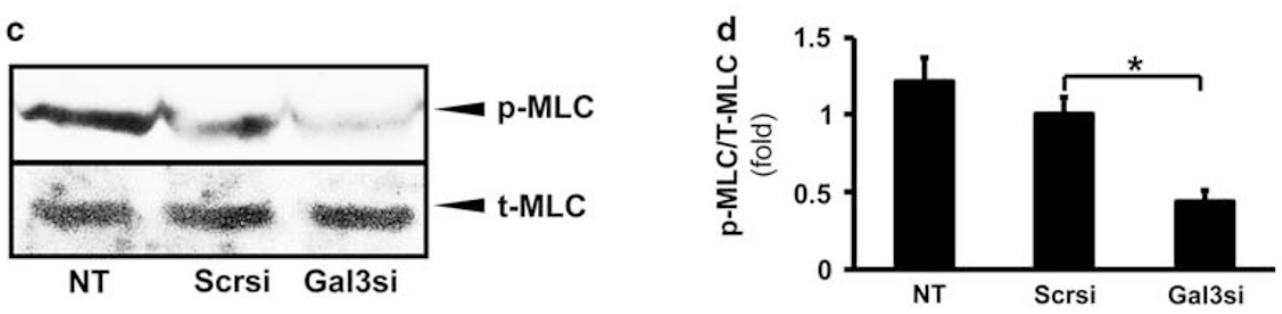

Figure 7 Hepatocellular carcinoma cell migration is regulated by a ROCK and MLCK-mediated pathway resulting in MLC2 phosphorylation. Hepa1-6 cells were incubated with Y-27632 (ROCK inhibitor, $10 \mu \mathrm{M}$ ), and a wound closure assay was performed. ROCK inhibition resulted in a significant decrease in the migratory rate compared with the control cells. (a and $\mathbf{b} ; N=4,{ }^{*} P<0.05$ ). The phosphorylation of MLC2 was examined as downstream target of galectin 3 and RhoA/ROCK by western blots (c). Densitometry based on three independent experiments showed that in the galectin 3 siRNA-transfected cells, the phosphorylation of MLC2 was significantly reduced (d, $\left.N=3,{ }^{*} P<0.05\right)$.

We have also tested the role of galectin 3 in vivo in the DEN-induced HCC model. The results indicated a decreased tumor burden, number of intrahepatic metastases, and a more differentiated tumor phenotype with the lack of vascular invasion in the galectin $3^{-1-}$ mice. HCC tumor cells and tumor-associated macrophages were both positive for galectin 3. A plausible explanation for this is the induction of NF- $\kappa \mathrm{B}$ transactivation, as we have shown in HCC tumor tissue and Hepa1-6 cells (Figure 4). NF- $\kappa$ B induction is an important step in HCC tumorigenesis, ${ }^{29-31}$ and its link to the increased HCC cell motility is well recognized. ${ }^{32,33}$ Galectin 3 induction of course can occur by other mechanisms as well, as it was shown that the epigenetic regulation of galectin 3 by $\beta 1$ integrin induces cell motility. ${ }^{31}$ Galectin 3 can also be involved in other regulatory pathways in cancer cell migration. The expression level of galectin 3 in colon cancer cells is correlated with cell migratory activity and this is mediated by K-Ras/Raf/Erk signaling. ${ }^{34}$ Furthermore, as galectin 3 is a binding partner for $\beta$-catenin in immortalized breast cancer and colon cancer cells, ${ }^{35}$ it could be involved in the regulation of $\mathrm{Wnt} / \beta$-catenin signaling cascade in HCC.

In addition our in vitro and in vivo data showed that galectin 3 deficiency in hepatoma cells is correlated with decreased proliferative activity and increased apoptosis (Figures $2 \mathrm{f}$ and $5 \mathrm{c}$ ). These are in an agreement to the previous findings that galectin 3 promotes cells proliferation and protect cells from proapoptotic stimuli. ${ }^{36,37}$

Galectin 3 has an important role in liver fibrosis by inducing the activation of hepatic stellate cells and promoting the deposition of the extracellular matrix. ${ }^{7,8}$ We have previously shown that the active myofibroblasts and Kupffer cells secrete galectin $3 .^{8}$ As the majority of HCCs arise in cirrhotic livers in humans, it is interesting to speculate that these cells beside tumor-associated macrophages could also be important paracrine sources of galectin 3 in HCC tumorigenesis.

In summary, in this paper we have shown that galectin 3 promotes HCC cell migration, by inducing RhoA GTPase activity, MLC2 phosphorylation, and actin rearrangement required for a motile phenotype. In vivo galectin $3^{-1-}$ mice developed smaller tumor burden with a more differentiated phenotype in response to the carcinogen DEN. Development of therapeutic strategies targeting galectin 3 could prevent invasion and metastasis, and this in turn can lengthen a progression-free period that could bridge to liver transplantation.

\section{ACKNOWLEDGMENTS}

We thank Dr Simon Cherry and staff (Center for Molecular and Genomic Imaging, UC Davis) for micro CT scan; and Dr Sridevi Devaraj (Texas Children's hospital) for providing the $\mathrm{PCMX-|KBa}$ plasmid.

\section{DISCLOSURE/CONFLICT OF INTEREST}

The authors declare no conflict of interest.

1. Llovet JM, Burroughs A, Bruix J. Hepatocellular carcinoma. Lancet 2003;362:1907-1917.

2. Altekruse SF, McGlynn KA, Reichman ME. Hepatocellular carcinoma incidence, mortality, and survival trends in the United States from 1975 to 2005. J Clin Oncol 2009;27:1485-1491. 
3. Liu FT. Molecular biology of lgE-binding protein, lgE-binding factors, and IgE receptors. Crit Rev Immunol 1990;10:289-306.

4. Newlaczyl AU, Yu LG. Galectin-3-a jack-of-all-trades in cancer. Cancer Lett 2011;313:123-128.

5. Henderson NC, Sethi T. The regulation of inflammation by galectin-3. Immunol Rev 2009;230:160-171.

6. MacKinnon AC, Farnworth SL, Hodkinson PS et al. Regulation of alternative macrophage activation by galectin-3. J Immunol 2008;180: 2650-2658.

7. Henderson NC, Mackinnon AC, Farnworth SL et al. Galectin-3 regulates myofibroblast activation and hepatic fibrosis. Proc Natl Acad Sci USA 2006:103:5060-5065.

8. Jiang JX, Chen X, Hsu DK et al. Galectin-3 modulates phagocytosisinduced stellate cell activation and liver fibrosis in vivo. Am J Physiol Gastrointest Liver Physiol 2012;302:G439-G446.

9. Hsu DK, Dowling CA, Jeng KC et al. Galectin-3 expression is induced in cirrhotic liver and hepatocellular carcinoma. Int J Cancer 1999;81: 519-526.

10. Matsuda Y, Yamagiwa Y, Fukushima $\mathrm{K}$ et al. Expression of galectin-3 involved in prognosis of patients with hepatocellular carcinoma. Hepatol Res 2008;38:1098-1111.

11. Strik HM, Deininger MH, Frank B et al. Galectin-3: cellular distribution and correlation with WHO-grade in human gliomas. J Neurooncol 2001:53:13-20.

12. Rabinovich GA, Toscano MA, Jackson SS et al. Functions of cell surface galectin-glycoprotein lattices. Curr Opin Struct Biol 2007;17:513-520.

13. Parri M, Chiarugi P. Rac and Rho GTPases in cancer cell motility control. Cell Commun Signal 2010;8:23.

14. Hsu DK, Yang RY, Pan Z et al. Targeted disruption of the galectin-3 gene results in attenuated peritoneal inflammatory responses. Am J Pathol 2000;156:1073-1083.

15. Van Antwerp DJ, Martin SJ, Kafri T et al. Suppression of TNF-alphainduced apoptosis by NF-kappaB. Science 1996;274:787-789.

16. Rubins NE, Friedman JR, Le PP et al. Transcriptional networks in the liver: hepatocyte nuclear factor 6 function is largely independent of Foxa2. Mol Cell Biol 2005;25:7069-7077.

17. Liu FT, Hsu DK, Zuberi Rl et al. Expression and function of galectin-3, a beta-galactoside-binding lectin, in human monocytes and macrophages. Am J Pathol 1995;147:1016-1028.

18. He G, Karin M. NF-kappaB and STAT3 - key players in liver inflammation and cancer. Cell Res 2011;21:159-168.

19. Hsu DK, Hammes SR, Kuwabara I et al. Human T lymphotropic virus-I infection of human $T$ lymphocytes induces expression of the beta-galactoside-binding lectin, galectin-3. Am J Pathol 1996;148: 1661-1670.

20. Liu L, Sakai T, Sano N et al. Nucling mediates apoptosis by inhibiting expression of galectin-3 through interference with nuclear factor kappaB signalling. Biochem J 2004;380(Pt 1):31-41.
21. Hakuma N, Kinoshita I, Shimizu $Y$ et al. E1AF/PEA3 activates the Rho/ Rho-associated kinase pathway to increase the malignancy potential of non-small-cell lung cancer cells. Cancer Res 2005;65:10776-10782.

22. Matsumura F, Totsukawa G, Yamakita Y et al. Role of myosin light chain phosphorylation in the regulation of cytokinesis. Cell Struct Funct 2001;26:639-644.

23. Caramel J, Quignon F, Delattre O. RhoA-dependent regulation of cell migration by the tumor suppressor hSNF5/INI1. Cancer Res 2008;68: 6154-6161.

24. Wong CC, Wong CM, Au SL et al. RhoGTPases and Rho-effectors in hepatocellular carcinoma metastasis: ROCK N'Rho move it. Liver Int; 30: 642-656.

25. Nangia-Makker $\mathrm{P}$, Balan $\mathrm{V}, \mathrm{Raz} \mathrm{A}$. Regulation of tumor progression by extracellular galectin-3. Cancer Microenviron 2008:1:43-51.

26. Genda T, Sakamoto M, Ichida T et al. Cell motility mediated by rho and Rho-associated protein kinase plays a critical role in intrahepatic metastasis of human hepatocellular carcinoma. Hepatology 1999;30: 1027-1036.

27. Kahsai AW, Cui J, Kaniskan $\mathrm{HU}$ et al. Analogs of tetrahydroisoquinoline natural products that inhibit cell migration and target galectin-3 outside of its carbohydrate-binding site. J Biol Chem 2008;283: 24534-24545.

28. Glinskii OV, Sud S, Mossine VV et al. Inhibition of prostate cancer bone metastasis by synthetic TF antigen mimic/galectin-3 inhibitor lactulose-L-leucine. Neoplasia 2012;14:65-73.

29. Pikarsky E, Porat RM, Stein I et al. NF-kappaB functions as a tumour promoter in inflammation-associated cancer. Nature 2004;431: 461-466.

30. Haybaeck J, Zeller N, Wolf MJ et al. A lymphotoxin-driven pathway to hepatocellular carcinoma. Cancer Cell 2009;16:295-308.

31. Margadant C, van den Bout I, van Boxtel AL et al. Epigenetic regulation of galectin-3 expression by beta 1 integrins promotes cell adhesion and migration. J Biol Chem 2012;287:44684-44693.

32. Kastl L, Sauer SW, Ruppert T et al. TNF-alpha mediates mitochondrial uncoupling and enhances ROS-dependent cell migration via NF-kappaB activation in liver cells. FEBS Lett 2014;588:175-183.

33. Li J, Lau G, Chen L et al. Interleukin 23 promotes hepatocellular carcinoma metastasis via NF-kappa B induced matrix metalloproteinase 9 expression. PLoS One 2012;7:e46264.

34. Wu KL, Huang EY, Jhu EW et al. Overexpression of galectin-3 enhances migration of colon cancer cells related to activation of the K-Ras-RafErk1/2 pathway. J Gastroenterol 2013;48:350-359.

35. Shimura T, Takenaka Y, Tsutsumi $\mathrm{S}$ et al. Galectin-3, a novel binding partner of beta-catenin. Cancer Res 2004;64:6363-6367.

36. Inohara $\mathrm{H}$, Akahani $\mathrm{S}, \mathrm{Raz} \mathrm{A}$. Galectin-3 stimulates cell proliferation. Exp Cell Res 1998:245:294-302.

37. Hu Z, Jiang $X, X u$ Y et al. Downregulation of galectin-3 by EGF mediates the apoptosis of HepG2 cells. Mol Cell Biochem 2012;369:157-165. 